Bismuth(III) bromide catalyzed synthesis of

Leave this area blank for abstract info. polyhydroquinoline derivatives via The Hantzsch reaction.

Joshua S. Yoo, Thomas J. Laughlin, Joseph J. Krob, Ram S. Mohan.*

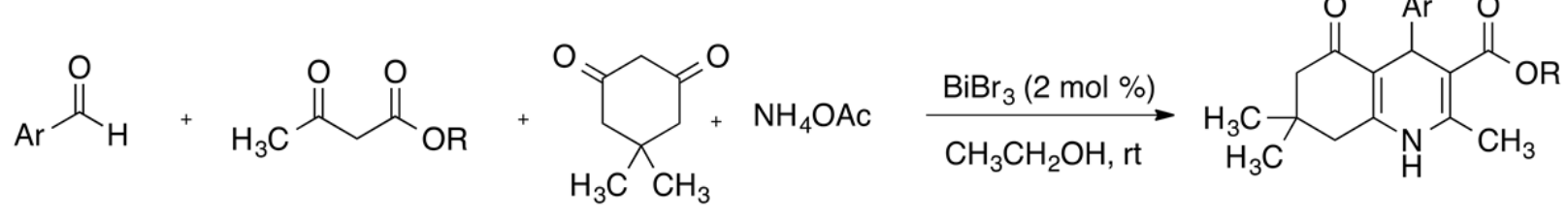


Bismuth(III) bromide catalyzed synthesis of polyhydroquinoline derivatives via The Hantzsch reaction

Joshua S. Yoo ${ }^{\text {a }}$, Thomas J. Laughlin, ${ }^{\text {a }}$ Joseph J. Krob ${ }^{\mathrm{a}}$ and Ram S. Mohan. ${ }^{\mathrm{a}}$

${ }^{a}$ Laboratory for Environmentally Friendly Organic Synthesis, Department of Chemistry, Illinois Wesleyan University, Bloomington, IL 61701 USA

Email: rmohan@iwu.edu

Abstract

Bismuth(III) bromide is an efficient catalyst for the one-pot multicomponent synthesis of polyhydroquinolines via the Hantzsch reaction. The mild reaction conditions, short reaction times, high yields and the remarkably low toxicity of bismuth compounds make this method especially attractive.

Keywords:

Bismuth bromide, Polyhydroquinolines, Hantzsch reaction, Multicomponent reaction, Green chemistry. 


\section{Bismuth(III) bromide catalyzed synthesis of polyhydroquinoline derivatives via}

The Hantzsch reaction.

The synthesis of 1,4-dihydropyridine derivatives such as polyhydroquinolines (PHQ) is of considerable interest due to their biological properties. Their derivatives such as nifedipine are calcium channel antagonists. ${ }^{1}$ Polyhydroquinolines bearing a tetraazole moiety have been shown to possess antimicrobial activity. ${ }^{2}$ 2,4-disubstituted polyhydroquinolines also show promise as antihyperglycemic and lipid modulating agents. ${ }^{3}$ Polyhydroquinolines have also been shown to reduce cellular tau levels and therefore hold promise in the search for therapies for Alzheimer's disease. ${ }^{4}$ Many PHQ derivatives also show activity against multidrug resistance proteins. ${ }^{5}$ Hence there has been considerable interest in methods for their synthesis. The most common route to polyhydroquinolines 5 involves a modified Hantzsch reaction ${ }^{6}$ involving the multi-component coupling of an aldehyde $\mathbf{1}$ with a $\beta$ ketoester (such as ethyl acetoacetate) 2, a diketone (such as dimedone) 3, and ammonium acetate 4 (Scheme 1).

Scheme 1

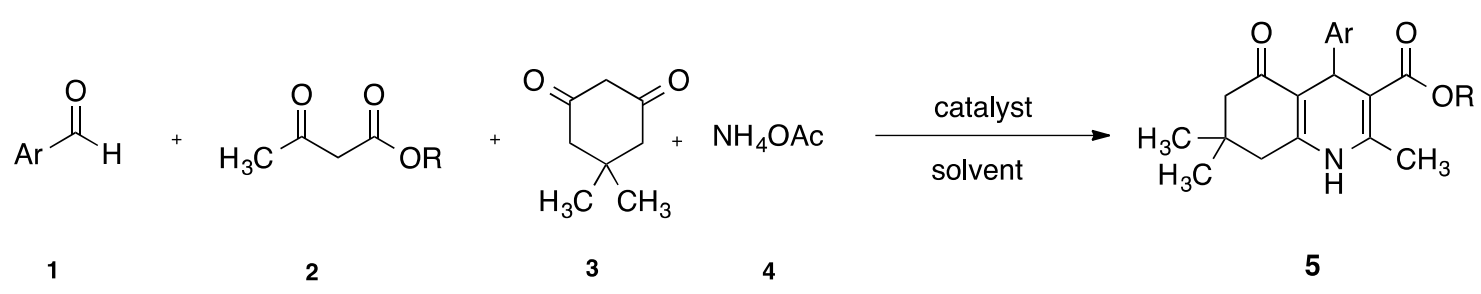

Some representative examples of catalysts used for this coupling include $\mathrm{I}_{2},{ }^{7}$ metal triflates, ${ }^{8}$ ceric ammonium nitrate, ${ }^{9}$ Baker's yeast, ${ }^{10}$ organocatalysts, ${ }^{11}$ zeolites, ${ }^{12} \mathrm{Ph}_{3} \mathrm{P},{ }^{13} \mathrm{GaCl}_{3},{ }^{14}$ thiourea dioxide, ${ }^{15}$ thiazolium ion, ${ }^{16}$ sulphamic acid, ${ }^{17} \mathrm{Al}_{2}\left(\mathrm{SO}_{4}\right)_{3},{ }^{18} \mathrm{La}_{2} \mathrm{O}_{3},{ }^{19}$ and nanoparticles. ${ }^{20}$ Syntheses of PHQs have also been carried out in various ionic liquids as solvents. ${ }^{21}$ Their syntheses have also been reported under catalyst-free conditions, but the 
methods suffer from longer reaction times. ${ }^{22}$ Solvent and catalyst-free methods involving grinding the reaction mixtures have also been reported and are certainly attractive from a green chemistry perspective. But these methods require the use of solvent for product isolation and are not always amenable to scale-up. ${ }^{23}$ PHQs have also been synthesized under microwave irradiation conditions. ${ }^{24}$ The most elegant synthesis of PHQs to date is their enantioselective synthesis using a phosphoric acid derived organocatalyst. ${ }^{25}$

Given our continued interest in bismuth(III) salts as catalysts due to their remarkably non toxic nature (many bismuth salts are even less toxic than $\mathrm{NaCl}$ ) and ease of handling, we explored the utility of bismuth bromide, $\mathrm{BiBr}_{3}$ as a catalyst for the synthesis of PHQs. ${ }^{26}$ Herein we report an efficient synthesis of a variety of polyhydroquinolines using bismuth(III) bromide as a catalyst in ethanol as the solvent (Table 1). The reactions are fast, and product is isolated by filtration of the reaction mixture. Hence no aqueous waste stream is generated. In the absence of $\mathrm{BiBr}_{3}$, the reactions took a considerably longer time and lower yields were obtained. For example, $p$-N,N-dimethylaminobenzaldehyde (Table 1, entry 2) yielded 61\% product $(\mathrm{t}=23 \mathrm{~h})$, and $p$-chlorobenzaldehyde (Table 1 , entry 4$)$ yielded $65 \%$ product $(\mathrm{t}=7 \mathrm{~h})$ under catalyst free conditions. We found that the reaction was also efficiently catalyzed by bismuth triflate (2.0 mol\%). For example, p-tolualdehyde (Table 1, entry 1) yielded 86\% product $(\mathrm{t}=2 \mathrm{~h}$ ), but owing to the higher cost of bismuth triflate ( $\$ 225 / 25 \mathrm{~g}$ from Acros Organics) relative to bismuth bromide ( $\$ 25 / 25 \mathrm{~g}$ ) and its increased moisture sensitivity, we chose bismuth bromide. Ytterbium triflate, $\mathrm{Yb}(\mathrm{OTf})_{3}(5.0 \mathrm{~mol} \%)$ has been reported as a catalyst $^{8 \mathrm{a}}$ for the formation of polyhydroquinolines but a higher catalyst loading ( 5 mol\%) and its high cost detract from its utility (\$395/25 g for the anhydrous salt, and \$136/25 g for the monohydrate). Although we used anhydrous ethanol as the reaction solvent, one cannot rule out hydrolysis of $\mathrm{BiBr}_{3}$ by adventitious water to generate $\mathrm{HBr}$, which could act as a Bronsted acid catalyst. In order to get some insight into the role of $\mathrm{BiBr}_{3}$ in the reaction, we 
carried out the reaction (Scheme 2) of $p$-chlorobenzaldehyde in the presence of $\mathrm{BiBr}_{3}(2.0$ mol\%) and solid potassium carbonate (10 mol\%). The $\mathrm{pH}$ of this reaction mixture was found to be $\sim 6-7$, and yet product was obtained in $86 \%$ yield suggesting that $\mathrm{BiBr}_{3}$ is acting as a Lewis acid and not just as a source of $\mathrm{HBr}$.

Scheme 2

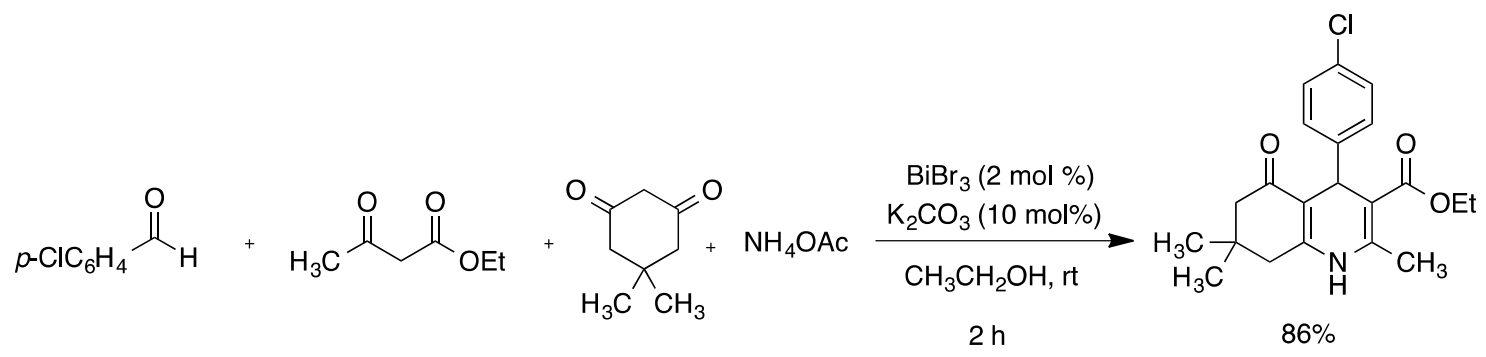

The mild reaction conditions with $\mathrm{BiBr}_{3}$ allow for easy scale-up as well. In summary, a mild and efficient method for the multicomponent synthesis of polyhydroquinolines using a relatively nontoxic and noncorrosive catalyst is reported. 
Table 1. Synthesis of polyhydroquinolines catalyzed by $\mathrm{BiBr}_{3}(2.0 \mathrm{~mol} \%){ }^{27}$

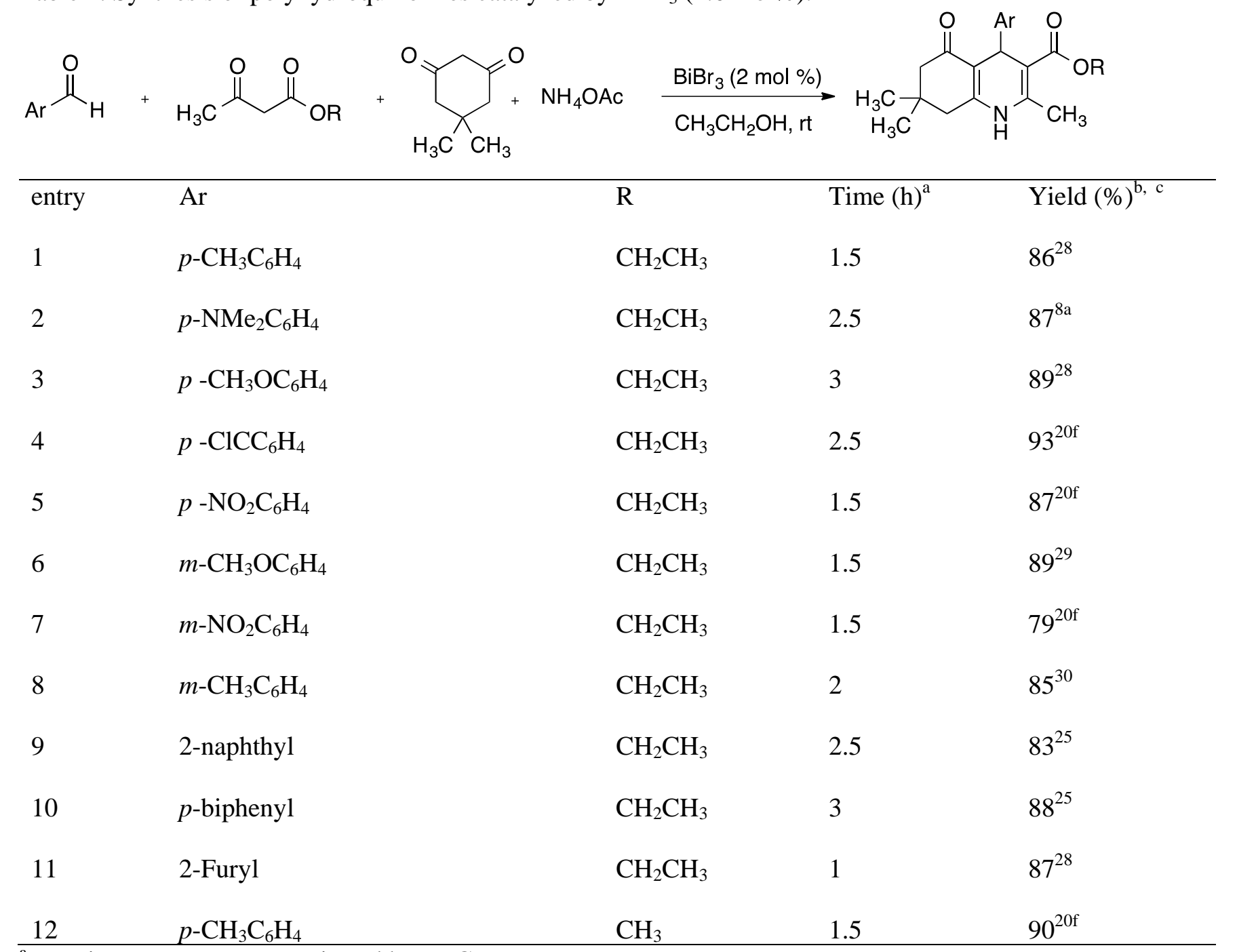

${ }^{\mathrm{a}}$ Reaction progress was monitored by TLC.

${ }^{\mathrm{b}}$ Refers to yield of isolated, purified product.

${ }^{\mathrm{c}}$ All products have been previously reported and were identified by comparison of melting point and their spectral data with those reported in the literature. Superscript against yield refers to literature reference for product. ${ }^{1} \mathrm{H}$ and ${ }^{13} \mathrm{C}-\mathrm{NMR}$ are provided in the SI section. 


\section{Acknowledgments}

This material is based upon work supported by the National Science Foundation under CHE 1229133, which funded the purchase of a $400 \mathrm{MHz}$ NMR spectrometer. We also acknowledge funding from The American Chemical Society-Petroleum Research Fund (ACS PRF\# 51036UR1).

\section{Supplementary Material}

Although all products have been previously reported, their spectral data is not readily available. ${ }^{1} \mathrm{H}$ and ${ }^{13} \mathrm{C}$ spectra not previously reported are included here.

\section{References}

1. (a) L. Rosenberger and D. J. Triggle in “Calcium and Drug Action”, G. B. Weiss, Ed., Plenum Press, New York, 1978, p 1. (b) P. A. van Zweiten and E. Schönbaum, Eds., Prog. Pharmacol., 2(1), 39 (1978). (c) Fleckenstein, A., Annu. Rev. Pharmacol. Toxicol., 1977, 17, 149.

2. Ladani, N.K.; Mungra, D.C.; Patel, M.P.; Patel R.G. Chinese Chem. Lett. 2011, 22, 1407

3. Kumar, A.; Sharma, S.; Tripathi, V.D.; Maurya, R.A.; Srivastava, S.P.; Bhatia, G.; Tamrakar, A.K.; Srivastava, A.K. Bioorganic \& Medicinal Chemistry 2010, 18, 4138.

4. Evans, C.G.; Jinwal, U.K.; Makley, L. N.; Dickey, C. A.; Gestwicki, J. E. Chem. Commun. 2011, 47, 529.

5. Miri, R.; Mehdipour, A. Bioorg. Med. Chem. 2008, 16, 8329.

6. Hantzsch, A. Ann. 1882, 215, 1.

7. Ko, S.; Sastry, M. N. V.; Lin, C.; Yao, C-F. Tetrahedron Lett. 2005, 46, 5771.

8. (a) Yb(OTf) : Wang, L-M.; Sheng, J.; Zhang, L.; Han, J-W.; Fan, Z-Y.; Tian, H.; Qian, C-T. Tetrahedron 2005, 61, 1539 (b) Sc(OTf) : Donelson, J. L.; Gibbs, R. A.; De, S. K. J. Mol. Cat. A:Chemical 2006, 256, 309.

9. Ko, S.; Yao, C-F. Tetrahedron 2006, 62, 7293.

10. Kumar, A.; Maurya, R. A. Tetrahedron Lett. 2007, 48, 3887. 
11. Kumar, A.; Maurya, R. A. Tetrahedron 2007, 63, 1946.

12. Gadekar, L.S.; Katkar, S.S.; Mane, S.R.; Arbad, B.R.; Lande, M.K. Bulletin Korean Chem. Soc. 2009, 30, 2532.

13. Debache, A.; Ghalem, W.; Boulcina, R.; Belfaitah, A.; Rhouati, S.; Carboni, B. Tetrahedron Lett. 2009, 50, 5248.

14. Patil, D.R.; Deshmukh, M.B.; Salunkhe, S.M.; Salunkhe, D. K.; Kolekar, G.B.; Anbhule, P.V. Der Pharma Chemica 2010, 2, 342.

15. Kumar, N.; Verma, S.; Jain, S.L. Chemistry Lett. 2012, 41, 920.

16. Fatma, S.; Ankit, P.; Singh, M.; Singh, S.B.; Singh, J. Synthetic Commun. 2014, 44, 1810.

17. Lambat, T.; Deo, S.; Deshmukh, T. J. Chem. Pharm. Res. 2014, 6, 888.

18. Kulkarni, P. J. Chil. Chem. Soc. 2014, 59, 2319.

19. Tekale, S.U.; Pagore, V.P.; Kauthale, S.S.; Pawar, R.P. Chinese Chem. Lett. 2014, 25, 1149.

20. (a) Ranjbar-Karimi, R.; Hashemi-Uderji, S.; Bazmandegan-Shamili, A. Chinese J. Chem.

2011, 29, 1624. (b) Shirini, F.; Atghia, S.V.; Khoshdel, M.A. Iranian J. Catal. 2011, 1, 93. (c)

Saikia, L.; Dutta, D.; Dutta, D.K. Catal. Commun., 2012, 19, 1. (d) Vahdat, S.M.; Chekin, F.;

Hatami, M.; Khavarpour, M.; Baghery, S.; Roshan-Kouhi, Z. Chin. J. Chem. 2013, 34, 758. (e)

Kiasat, A. R.; Almasi, H.; Saghanezhad, S. J. Rev. Roum. Chim. 2014, 59, 61. (f) Nasr-Esfahani, M.; Hoseini, S.J.; Montazerozohori, M.; Mehrabi, R.; Nasrabadi, H. J. Mol. Catal. A: Chemical 2014, 382, 99.

21. (a) Nirmal, J.P.; Dadhaniya, P.V.; Patel, M.P.; Patel, R.G. Indian Journal of Chemistry, Section B 2010, 49B, 587. (b) Rajendran, A.; Karthikeyan, C.; Rajathi, K. International Journal of ChemTech Research 2011, 3, 810. (c) Raghuvanshi, D.S.; Singh, K.N. Indian Journal of 
Chemistry, Section B 2013, 52B, 1218. (d) Rostamnia, S.; Hassankhani, A. Synlett 2014, 25, 2753.

22. Undale, K. A.; Shaikh, T. S.; Gaikwad, D. S.; Pore, D. M. Comptes Rendus Chimie 2011, 14, 511.

23. (a) Arumugam, P.; Perumal, P.T. Indian Journal of Chemistry, Section B 2008, 47B, 1084.

(b) Kumar, S.; Sharma, P.; Kapoor, K.K.; Hundal, M.S. Tetrahedron 2008, 64, 536.

24. (a) Zhang, X-L.; Sheng, S-R.; Liu, X-L.; Liu, X-L. ARKIVOC 2007, xiii, 79. (b) Das, S.;

Santra, S.; Roy, A.; Urinda, S.; Majee, A.; Hajra, A. Green Chemistry Letters and Reviews 2012, 5, 97. (c) Joshi, V.M.; Pawar, R.P. European Chemical Bulletin 2013, 2, 679.

25. Evans, C.G.; Gestwicki, J.E. Org. Lett. 2009, 11, 2957.

26. For a review on the utility of bismuth compounds in organic synthesis, see: (a) Ollevier, T. Org. Biomol. Chem. 2013,11, 2740. (b) Krabbe, S. W.; Bothwell, J. M.; Mohan, R. S. Chem. Soc. Rev. 2011, 40, 4649. For some recent examples of the use of bismuth(III) compounds in organic synthesis see (c) Coca, A.; Feinn, L.; Dudley, J. Synthetic Commun. 2015, 45, 1023. (d) Sabitha, G.; Shankaraiah, K.; Sindhu, K.; Latha, B. M. Synthesis 2015, 47, 124. (e) Sheng, J.; Wu, J. Org. Biomol. Chem. 2014, 12, 7629. (f) Moskalenko, A. I.; Boev, V. I. Russian. J. Org. Chem. 2014, 50, 1117. (g) Nitsch, D.; Bach, T. J. Org. Chem. 2014, 79, 6372. (h) Murai, M.; Origuchi, K.; Takai, K. Org. Lett. 2014, 16, 3828. (i) Rasmussen, M. R.; Marqvorsen, M. H. S.; Kristensen, S. K.; Jensen, H. H. J. Org. Chem. 2014, 79, 11011. (j) Schneider, A. E.; Beisel, T.; Shemet, A.; Manolikakes, G. Org. Biomol. Chem. 2014, 12, 2356.

27. Representative procedure: A homogeneous mixture of $p$-tolualdehyde (0.5000 g, $4.16 \mathrm{mmol})$, dimedone (0.6417 g, $4.58 \mathrm{mmol}, 1.1$ equiv.), ethyl acetoacetate (0.5968 g, $0.58 \mathrm{~mL}, 4.58 \mathrm{mmol}$, 1.1 equiv.), and ammonium acetate (0.3528 g, $4.58 \mathrm{mmol}, 1.1$ equiv.) was stirred in anhydrous 
ethanol $(10.0 \mathrm{~mL})$ at room temperature as $\operatorname{BiBr}_{3}(0.0373 \mathrm{~g}, 2.0 \mathrm{~mol} \%)$ was added. The reaction progress was monitored by TLC (2,4-DNP stain). After $1.5 \mathrm{~h}$, the reaction mixture was poured onto $20 \mathrm{~g}$ of ice and the resulting yellow precipitate was collected via suction filtration. The crude product was recrystallized using anhydrous ethanol (approximately $30 \mathrm{~mL}$ ) to yield 1.2694 g (86\% yield) of a slightly off-white, powdery compound. Mpt: $258-259{ }^{\circ} \mathrm{C}$ (Lit: $258-259{ }^{\circ} \mathrm{C}$ ). 28. Heravi, M. M.; Saeedi, M.; Karimi, N.; Zakeri, M.; Beheshtiha, Y. S.; Davoodnia, A. Synthetic Commun. 2010, 40, 523.

29. Maleki, B.; Tayebee, R.; Kermanian, M.; Ashrafi, S. S. J. Mex. Chem. Soc. 2013, 57, 290.

30. Ghasemzadeh, M. A.; Safaei-Ghomi, H. J. Chem. Res. 2014, 38, 313. 